\title{
A systematic review of research studies on the estimation of net primary productivity in the Three-River Headwater Region, China
}

\author{
SUN Qingling ${ }^{1,2}$, "LI Baolin ${ }^{1,2,3}$, ZHOU Chenghu ${ }^{1,2,3}$, LI Fei $^{4}$, ZHANG Zhijun $^{4}$, \\ DING Lingling ${ }^{4}$, ZHANG Tao ${ }^{1,2}, \mathrm{XU}_{\text {Lili }^{1,2}}$
}

1. State Key Laboratory of Resources and Environmental Information System, Institute of Geographic Sciences and Natural Resources Research, CAS, Beijing 100101, China;

2. University of Chinese Academy of Sciences, Beijing 100049, China;

3. Jiangsu Center for Collaborative Innovation in Geographical Information Resource Development and Application, Nanjing 210023, China;

4. Remote Sensing Monitoring Center of Qinghai Ecology and Environment, Xining 810007, China

\begin{abstract}
The Three-River Headwater Region (TRHR), known as the "Water Tower of China", is an important ecological shelter for national security interests and regional sustainable development activities for many downstream regions in China and a number of Southeast Asian countries. The TRHR is a high-elevation, cold environment with a unique, but typical alpine vegetation system. Net primary productivity (NPP) is a key vegetation parameter and ecological indicator that can reflect both natural environmental changes and carbon budget levels. Given the unique geographical environment and strategic location of the TRHR, many scholars have estimated NPP of the TRHR by using different methods; however, these estimates vary greatly for a number of reasons. To date, there is no paper that has reviewed and assessed NPP estimation studies conducted in the TRHR. Therefore, in this paper, we (1) summarized the related methods and results of NPP estimation in the TRHR in a systematic review of previous research; (2) discussed the suitability of existing methods for estimating NPP in the TRHR and highlighted the most significant challenges; and (3) assessed the estimated NPP results. Finally, developmental directions of NPP estimation in the TRHR were prospected.
\end{abstract}

Keywords: Three-River Headwater Region (TRHR); net primary productivity (NPP); estimation methods; NPP models; ecological parameters

Received: 2016-06-24 Accepted: 2016-07-26

Foundation: National Key Research and Development Program of China, No.2016YFC0500205; National Basic Research Program of China (973 Program), No.2015CB954103, No.2015CB954101

Author: Sun Qingling (1991-), PhD Candidate, specialized in ecological modelling. E-mail: sunq1@lreis.ac.cn

"Corresponding author: Li Baolin (1970-), PhD and Professor, specialized in environmental remote sensing and regional ecological modelling. E-mail: libl@1reis.ac.cn 


\section{Introduction}

Vegetation productivity is the basis of energy flow and material circulation in ecosystems (Running, 2012). Researchers from different disciplines have proposed a variety of concepts to describe vegetation productivity. In traditional biomass surveys, accumulation of vegetation production or change in biomass over a specific period is usually used to represent productivity (Lieth, 1973). With the increase in large-scale productivity studies and progress in understanding plant ecophysiological processes, gross primary productivity (GPP) and net primary productivity (NPP) were proposed to represent vegetation productivity (Lieth and Whittaker, 1975; Liu et al., 1997; Zhou and Wang, 2003). Defined as the carbon (or dry matter) fixed by green plants per unit time and space, NPP is closely related to the carbon sink of ecosystems. NPP is also a quantitative measure of the earth's ability to support life and the ecosystems' ability to maintain sustainable development. Therefore, NPP has received extensive attention and has become one of the foci of various international research programs (Zhang, 1992; Zhou and Zhang, 1995; Fang et al., 2000).

The Three-River Headwater Region (TRHR), known as the "Water Tower of China", is the source of the Yangtze, Yellow, and Lancang rivers. Geographically, the TRHR is located in the south of Qinghai Province, ranging from $31^{\circ} 39^{\prime}-36^{\circ} 16^{\prime} \mathrm{N}$ and $89^{\circ} 24^{\prime}-102^{\circ} 23^{\prime} \mathrm{E}$. The administrative scope of TRHR includes 16 counties in four Tibetan autonomous prefectures (Yushu, Guoluo, Hainan, and Huangnan), as well as the Tanggula town in Golmud City, with an area of approximately $36.3 \times 10^{4} \mathrm{~km}^{2}$ (Figure 1). The TRHR is an important ecological shelter for national security interests and regional sustainable development activities for many downstream regions in China and a number of Southeast Asian countries. However, it is also one of the most vulnerable and sensitive terrestrial ecosystems in China (Qin, 2014). As the hinterland and main body of the world's "Third Pole", the TRHR has an average altitude above $4000 \mathrm{~m}$. It has a unique, yet typical alpine vegetation system, and plays an important role in the studies of global change and vegetation's responses to the change (Liu et al., 2013).

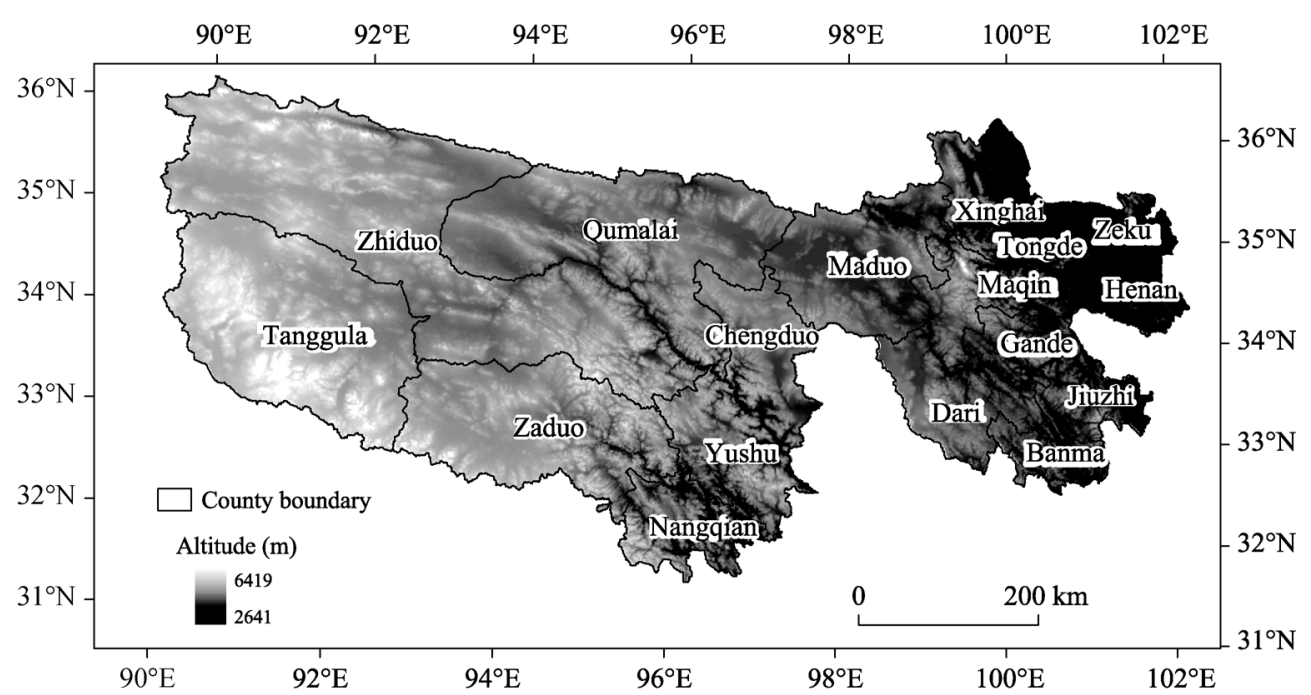

Figure 1 Geographical location and scope of the TRHR 
In the past few decades, ecosystems in the TRHR have experienced significant degeneration characterized by grassland degradation, desertification, and an overall reduction in agriculture and animal husbandry production (Li et al., 2004; Tang et al., 2006; Shao et al., 2010). In 2000, Qinghai Province established a provincial nature reserve in the TRHR that has been a national nature reserve since 2003. In 2005, the State Council of China invested 7.5 billion yuan to launch several ecological protection and construction projects in the TRHR, including degraded grassland restoration, local wetland protection, livestock reduction, and management of "black soil beach" (Shao and Fan, 2012). In this context, a comprehensive understanding of the patterns, variation trends, and impact factors of vegetation productivity is pivotal to the policy-making for ecological protection and assessment of ecological engineering in the TRHR.

Although many scholars have applied different methods to estimate NPP in the TRHR, which has effectively promoted research into vegetation productivity and regional carbon accounting, NPP estimation still has many uncertainties and the results vary widely for a variety of reasons. Therefore, based on previous studies, we aimed to systematically summarize the estimation methods and results of NPP in the TRHR. By analyzing these methods, we discuss their suitability and highlight their main challenges when applied to the TRHR. This review also provides an assessment of the existing NPP estimation results. Finally, future developmental directions of NPP estimation in the TRHR are proposed.

\section{Estimation methods}

Since the late 20th century, many scholars have estimated NPP in the TRHR. The methods they used can be broadly divided into two categories: field measurements and model simulations.

\subsection{Field measurements}

Field surveys of NPP usually start by measuring plant biomass (Fan, 2003), which includes both aboveground and underground parts of plants. Aboveground NPP is approximately equal to the maximum standing aboveground biomass during one year for deciduous grasses and crops (Luo et al., 2004; $\mathrm{Xu}, 2010$ ). For evergreen grasses and shrubs, the aboveground biomass needs to be combined with plant longevity to obtain the aboveground NPP. For trees, the aboveground biomass is usually first measured through average sample tree determination or allometry relationships with the observed data, and then the aboveground NPP is further estimated based on the age or growth rate of trees (Zhou and Wang, 2003).

Underground biomass measurements involve full digging, sampling, and ingrowth coring methods. There are three primary methods for estimating underground NPP based on the measurement of underground biomass. The first method directly measures the changes in live root biomass and the losses from decay and animal grazing. While in theory this method provides the closest estimate to the true NPP, taking actual measurements has proven quite difficult (Zhou, 2001). The second method for estimating underground NPP is calculating the difference between the maximum and minimum root biomass during the study period. This method is relatively simple, but it requires multiple measurements of the root biomass (Zhou, 2001). The third strategy, using both underground root biomass and root turnover 
fraction to estimate underground NPP, is the most commonly used method (Gill et al., 2002; Zhao, 2009). Besides, with the development of computer technology and image-processing techniques, the minirhizotron is also applied to measure underground NPP. However, this application is currently limited by the relatively high costs and technical requirements for researchers to conduct the measurements.

\subsection{Model simulations}

NPP models are generally divided into three categories: (1) statistical models (also known as climate-related models), (2) parametric models (also known as light use efficiency (LUE) models), and (3) process models (also known as mechanistic models) (Ruimy et al., 1994; Cramer and Field, 1999; Cramer et al., 1999).

However, with the development of NPP modeling, we believe that this classification may no longer fully and unambiguously summarize the existing NPP models. For example, some statistical models were not based on climate data, but rather utilized remote sensing (RS) vegetation index. Some parametric models were not based on LUE, but referred to climate data instead. RS-process coupled models, which have been widely used, should also be considered and included in the classification. Therefore, NPP models are divided into four categories in this study, according to the primary data used and whether they consider ecophysiological mechanisms: (1) climate models, (2) remote sensing models, (3) process models, and (4) RS-process coupled models.

\subsubsection{Climate models}

Climate models are driven only by climatic data. As such, simulated NPP using this type of model only reflects potential vegetation productivity (or climatic productivity). According to the existing studies of the TRHR, climate models can be further subdivided into climate-related models, production potential models, and the classification indices model (CIM).

Climate-related models estimate NPP through empirical regression between NPP and climate data, including temperature and precipitation. Guo et al. (2013) and $\mathrm{Li}$ and Zhang (2014) used the Thornthwaite Memorial model to estimate climatic productivity of the TRHR. Guo et al. (2008) used both the Miami and Thornthwaite Memorial models to estimate grassland NPP of Xinghai County in the TRHR.

Production potential models usually reflect combined influences of light, temperature, and water conditions on vegetation productivity. In general, photosynthetic potential productivity is first calculated using solar radiation data. Then, temperature data is applied to revise the photosynthetic potential productivity to obtain the light-temperature potential productivity, which is further revised using precipitation and other climatic data to acquire the climate productivity. For example, $\mathrm{Li}$ (2010) used solar radiation, temperature, precipitation, and annual climate change, as well as disaster related data, to obtain the climate productivity of natural grasslands in the TRHR.

The CIM estimates NPP based on the integrated orderly classification system of grassland (IOCSG). The moisture index $(\mathrm{K})$ and $\geqslant 0^{\circ} \mathrm{C}$ annual average cumulative temperature $\left(\sum \theta\right)$ are two primary model parameters used in the CIM. NPP is acquired from the specific posi- 
tion of the grassland in the IOCSG, which is determined by the two parameters (Lin, 2009). Wang (2013) applied the CIM model to estimate alpine grassland NPP in the TRHR, and concluded that the CIM was more accurate than the climate-related models.

\subsubsection{Remote sensing models}

Remote sensing models can be divided into statistical models and parametric models according to the calculation methods they use. RS statistical models estimate vegetation productivity based on a variety of vegetation indices. The most commonly used vegetation indices are the normalized difference vegetation index (NDVI) and the enhanced vegetation index (EVI) (Ma, 2008; Chen et al., 2011; Han, 2015). Studies have shown that NDVI was more suitable for alpine meadow, whereas EVI might be more suitable for alpine steppe (Du et al., 2011).

RS parametric models combine LUE, photosynthetically active radiation (PAR), and fraction of absorbed photosynthetically active radiation (fAPAR) to estimate NPP (Monteith, 1972; Kumar and Monteith, 1981). This type of model is based on the resource balance theory, which indicates that any resource limiting plant growth can be utilized to estimate NPP through conversion factors. RS parametric models utilize PAR, an important limiting resource in photosynthesis, and the concept of LUE to convert absorbed PAR to NPP. RS parametric models, which include CASA (Wu et al., 2011a; Cai et al., 2013; Zhang et al., 2014; Chen, 2015) and GLO-PEM (Xiao et al., 2009; Fan et al., 2010a; Shao and Fan, 2012), are broadly applied in the TRHR.

\subsubsection{Process models}

Process models differ substantially from the two types of models described above. As the name implies, a process model simulates plant physiological and ecological processes simultaneously with influencing factors and feedback mechanisms. Process models usually consider the soil-plant-atmosphere continuum as an entire system, and often include photosynthesis, respiration, evaporation, transpiration, and stomatal conductance modules. At present, specific applications of process models to estimate NPP in the TRHR have not yet been reported. However, applications have been reported for the Qinghai-Tibet Plateau. Zhou et al. (2004), Zhuang et al. (2010), and Yan et al. (2015) used different versions of TEM to simulate NPP on the Qinghai-Tibet Plateau. Zhang et al. (2007) applied CENTURY to estimate vegetation productivity and soil organic carbon on the Plateau. Ye (2010) and Qi et al. (2012) utilized Biome-BGC to simulate the temporal variation in NPP on the Qinghai-Tibet Plateau and the impacts of warming on carbon fluxes in an alpine meadow ecosystem, respectively. Concurrently, Piao et al. (2012) estimated NPP dynamics of the Qinghai-Tibetan grasslands over the past five decades based on ORCHIDEE. These studies are able to provide a reference for NPP estimation in the TRHR; however, specific quantities and detailed changes in NPP within the TRHR cannot be derived.

\subsubsection{RS-process coupled models}

RS-process coupled models incorporate the advantages of both process models and RS parametric models and have been gradually developed into an important means of estimating NPP (Feng et al., 2004, 2014). In general, there are two kinds of coupling methods. In the 
first method, simplified ecological processes are added to the RS parametric models to enhance the model mechanisms. In the second method, RS techniques are added to the existing process models to address the challenges of model parameterization, error evaluation, and scale transformation faced by most process models.

Wang et al. (2009) developed GLOPEM-CEVSA from a RS parametric model, GLOPEM, and a process model, CEVSA, using the first coupling method, and then utilized GLOPEM-CEVSA to estimate the spatio-temporal distribution of NPP in the TRHR. Global MODIS NPP product is also calculated based on a RS-process coupled model (also known as MOD17A3 algorithm). Guo et al. (2006) and Zhang et al. (2015a) both used MODIS NPP to analyze the spatio-temporal patterns of vegetation productivity in the TRHR. A typical example of the second coupling method is the BEPS model (Liu et al., 1997). BEPS was originally built using the biological principles of the FOREST-BGC with some modifications. The model integrated RS land cover and leaf area index (LAI) to recognize physiological differences among vegetation types and to facilitate scale transformation from leaf level to the whole canopy. Additionally, the model included an advanced canopy radiation sub-model to quantify effects of canopy architecture on the distribution of radiation and photosynthesis in the canopy. Although BEPS model is yet to be applied to the TRHR, its reliability has already been verified in Northern Tibet (Zheng, 2006).

\section{Estimated results}

At the regional scale, previous studies usually estimated NPP pixel by pixel based on vegetation type, and provided mean NPP of the study area explicitly. Therefore, mean NPP estimates for the entire TRHR were systematically summarized and compared in this study. From Tables 1 and 2, it is evident that mean NPP differs substantially among various studies conducted in the TRHR. For all the vegetation, estimated mean NPP of the TRHR was approximately $258.99 \pm 172.95 \mathrm{~g} \mathrm{C} \cdot \mathrm{m}^{-2} \cdot \mathrm{yr}^{-1}$, with the highest NPP of $570.35 \mathrm{~g} \mathrm{C} \cdot \mathrm{m}^{-2} \cdot \mathrm{yr}^{-1}$ estimated by Thornthwaite Memorial (Guo et al., 2013) and the lowest NPP of $143.17 \mathrm{~g}$ $\mathrm{C} \cdot \mathrm{m}^{-2} \cdot \mathrm{yr}^{-1}$ estimated using GLOPEM-CEVSA (Wang et al., 2009). The highest NPP estimate was approximately four times the lowest NPP estimate. For the grassland, which is the most widely distributed vegetation type in the TRHR accounting for $68 \%$ of the total area, simulated mean NPP was approximately $202.65 \pm 129.96 \mathrm{~g} \mathrm{C} \cdot \mathrm{m}^{-2} \cdot \mathrm{yr}^{-1}$. The highest grassland NPP estimate was $481.44 \mathrm{~g} \mathrm{C} \cdot \mathrm{m}^{-2} \cdot \mathrm{yr}^{-1}$ simulated by Li and Zhang (2014) using Thornthwaite Memorial, and the lowest grassland NPP estimate was $61.42 \mathrm{~g} \mathrm{C} \cdot \mathrm{m}^{-2} \cdot \mathrm{yr}^{-1}$ calculated by Wang (2013) using CASA. The former estimate was approximately 7.8 times higher than the latter.

Among different estimation models (Figure 2), climate models produced the highest mean NPP compared with other types of models. Estimated mean NPP of all the vegetation in the TRHR based on climate models was approximately $453.23 \pm 252.30 \mathrm{~g} \mathrm{C} \cdot \mathrm{m}^{-2} \cdot \mathrm{yr}^{-1}$, and mean grassland NPP was approximately $283.28 \pm 170.44 \mathrm{~g} \mathrm{C} \cdot \mathrm{m}^{-2} \cdot \mathrm{yr}^{-1}$. The second highest estimate was produced using RS models, which estimated mean NPP of all the vegetation in the TRHR to be $165.61 \pm 69.42 \mathrm{~g} \mathrm{C} \cdot \mathrm{m}^{-2} \cdot \mathrm{yr}^{-1}$ and mean NPP of grassland to be $147.68 \pm 98.08 \mathrm{~g}$ $\mathrm{C} \cdot \mathrm{m}^{-2} \cdot \mathrm{yr}^{-1}$. RS-process coupled models produced the lowest NPP. Estimated mean NPP of 
all the vegetation was $143.17 \pm 100.53 \mathrm{~g} \mathrm{C} \cdot \mathrm{m}^{-2} \cdot \mathrm{yr}^{-1}$, and mean NPP of grassland was 113.89 $\pm 65.57 \mathrm{~g} \mathrm{C} \cdot \mathrm{m}^{-2} \cdot \mathrm{yr}^{-1}$.

Table 1 Estimated mean NPP of the TRHR in different studies

\begin{tabular}{|c|c|c|c|c|c|}
\hline $\begin{array}{l}\text { Study } \\
\text { area }\end{array}$ & $\begin{array}{l}\text { Vegetation } \\
\text { type }\end{array}$ & Method \& Model & $\begin{array}{l}\text { Study } \\
\text { period }\end{array}$ & 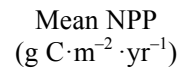 & Reference \\
\hline TRHR & Grassland & $\begin{array}{l}\text { Climate model } \\
\text { (Thornthwaite Memorial) }\end{array}$ & $2002-2010$ & 481.44 & Li and Zhang, 2014 \\
\hline TRHR & Grassland & $\begin{array}{l}\text { Climate model (Produc- } \\
\text { tion potential model) }\end{array}$ & 1971-2003 & 225.00 & Li, 2010 \\
\hline TRHR & Grassland & Climate model (Miami) & 2005-2006 & 211.92 & Wang, 2013 \\
\hline TRHR & Grassland & Climate model (CIM) & 2005-2006 & 214.75 & Wang, 2013 \\
\hline TRHR & Grassland & $\begin{array}{l}\text { Remote sensing model } \\
\text { (CASA) }\end{array}$ & 2005-2006 & 61.42 & Wang, 2013 \\
\hline TRHR & Grassland & $\begin{array}{l}\text { RS-process coupled model } \\
\text { (MOD17A3) }\end{array}$ & 2005-2006 & 93.98 & Wang, 2013 \\
\hline TRHR & Grassland & $\begin{array}{l}\text { RS-process coupled model } \\
\text { (MOD17A3) }\end{array}$ & 2000-2010 & 86.80 & Zhang et al., 2015a \\
\hline TRHR & All the vegetation & $\begin{array}{l}\text { Climate model } \\
\text { (Thornthwaite Memorial) }\end{array}$ & 1960-2011 & 570.35 & Guo et al., 2013 \\
\hline TRHR & All the vegetation & Climate model (Miami) & 2004-2008 & 486.90 & Cai et al., 2013 \\
\hline TRHR & All the vegetation & $\begin{array}{l}\text { Climate model } \\
\text { (Zhou Guangsheng) }\end{array}$ & 2004-2008 & 302.45 & Cai et al., 2013 \\
\hline TRHR & All the vegetation & Climate model (CASA) & $2001-2010$ & 169.02 & Zhang et al., 2014 \\
\hline TRHR & All the vegetation & Climate model (CASA) & 2004-2008 & 168.68 & Cai et al., 2013 \\
\hline TRHR & All the vegetation & $\begin{array}{l}\text { Remote sensing model } \\
\text { (CASA) }\end{array}$ & 2010 & 146.66 & Wo et al., 2014 \\
\hline TRHR & All the vegetation & $\begin{array}{l}\text { Remote sensing model } \\
\text { (CASA) }\end{array}$ & $\begin{array}{l}2003,2008, \\
2013\end{array}$ & 148.82 & Chen, 2015 \\
\hline TRHR & All the vegetation & $\begin{array}{l}\text { Remote sensing model } \\
\text { (GLOPEM) }\end{array}$ & 1988-2004 & 194.85 & Shao and Fan, 2012 \\
\hline TRHR & All the vegetation & $\begin{array}{l}\text { RS-process coupled model } \\
\text { (GLOPEM-CEVSA) }\end{array}$ & 1988-2004 & 143.17 & Wang et al., 2009 \\
\hline
\end{tabular}

Table 2 Estimated mean NPP of different vegetation types in the TRHR

\begin{tabular}{lccccc}
\hline \multirow{2}{*}{$\begin{array}{l}\text { Vegetation } \\
\text { type }\end{array}$} & \multicolumn{5}{c}{ Mean NPP $\left(\mathrm{g} \mathrm{C} \cdot \mathrm{m}^{-2} \cdot \mathrm{yr}^{-1}\right)$} \\
\cline { 2 - 6 } & Shao and Fan, 2012 & Cai et al., 2013 & Wo et al., 2014 & Wang et al., 2009 & Guo et al., 2006 \\
\hline Grassland & 218.74 & $/$ & 162.87 & 160.90 & $/$ \\
Alpine steppe & $/$ & 129.41 & $/$ & $/$ & 79.34 \\
Alpine meadow & $/$ & 188.95 & $/$ & $/$ & 89.38 \\
Forest & 405.20 & $/$ & 279.81 & 267.90 & $/$ \\
Shrub & 156.04 & $/$ & $/$ & $/$ & $/$ \\
Farmland & 289.22 & $/$ & 256.28 & 222.94 & $/$ \\
Desert & 21.48 & $/$ & 62.81 & 36.13 & $/$ \\
Marsh & 127.09 & $/$ & $/$ & 161.36 & $/$ \\
\hline
\end{tabular}




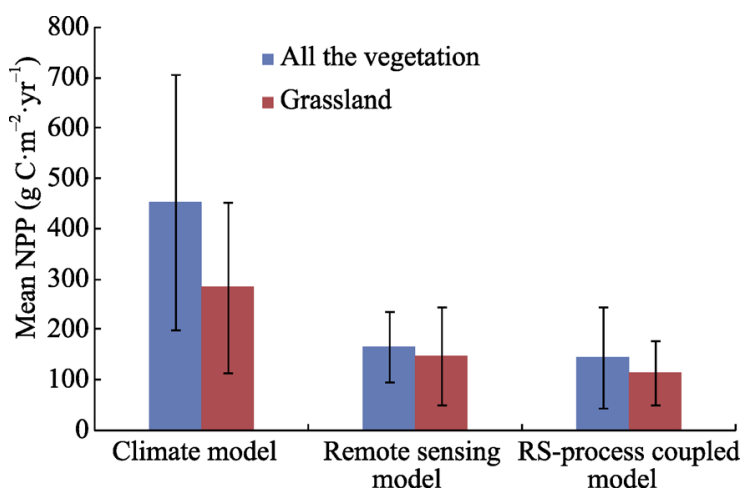

Figure 2 Comparison of estimated NPP based on different models in the TRHR

$130.79 \pm 73.27 \mathrm{~g} \mathrm{C} \cdot \mathrm{m}^{-2} \cdot \mathrm{yr}^{-1}$.

In terms of different vegetation types, estimated mean NPP displayed the following trend: forest $>$ farmland $>$ grassland $>$ desert (Table 2). Specifically, mean NPP estimates of forest, farmland, grassland, and desert in the TRHR were $317.64 \pm 170.06 \mathrm{~g} \mathrm{C} \cdot \mathrm{m}^{-2} \cdot \mathrm{yr}^{-1}, 256.15 \pm$ $130.41 \mathrm{~g} \mathrm{C} \cdot \mathrm{m}^{-2} \cdot \mathrm{yr}^{-1}, 130.79 \pm 73.27 \mathrm{~g} \mathrm{C} \cdot \mathrm{m}^{-2} \cdot \mathrm{yr}^{-1}$, and $40.14 \pm 25.99 \mathrm{~g} \mathrm{C} \cdot \mathrm{m}^{-2}$. $\mathrm{yr}^{-1}$, respectively. For the grassland, estimated NPP of alpine meadow was generally greater than that of alpine steppe (Guo et al., 2006; Cai et al., 2013), which was also observed in NPP field measurements. Measured NPP of alpine meadow was usually 1-3 times higher than that of alpine steppe (Table 3).

Table 3 Measured grassland NPP at different sites in the TRHR

\begin{tabular}{|c|c|c|c|c|c|c|c|}
\hline Site & Latitude & Longitude & Altitude & $\begin{array}{l}\text { Vegetation } \\
\text { type }\end{array}$ & Year & $\begin{array}{c}\text { Measured } \\
\operatorname{NPP}\left(\mathrm{g} \mathrm{C}^{-}\right. \\
\left.\mathrm{m}^{-2} \cdot \mathrm{yr}^{-1}\right)\end{array}$ & $\begin{array}{c}\text { Data } \\
\text { source }\end{array}$ \\
\hline Zhenqin & $\mathrm{N} 33^{\circ} 24^{\prime} 30^{\prime \prime}$ & $\mathrm{E} 97^{\circ} 18^{\prime} 00^{\prime \prime}$ & $4250 \mathrm{~m}$ & $\begin{array}{l}\text { Alpine mea- } \\
\text { dow }\end{array}$ & $\begin{array}{c}2010- \\
2011\end{array}$ & 118.41 & Fan, 2003 \\
\hline Wudaoliang & $\mathrm{N} 35^{\circ} 12^{\prime} 56^{\prime \prime}$ & $\mathrm{E} 93^{\circ} 04^{\prime} 05^{\prime \prime}$ & $4626 \mathrm{~m}$ & Alpine steppe & 2000 & 53.55 & Luo et al., 2004 \\
\hline Tuotuohe & $\mathrm{N} 34^{\circ} 18^{\prime} 51^{\prime \prime}$ & E92 $32^{\prime} 52^{\prime \prime}$ & $4582 \mathrm{~m}$ & Alpine steppe & 2000 & 69.30 & Luo et al., 2004 \\
\hline Dawu & $\mathrm{N} 34^{\circ} 23^{\prime} 24^{\prime \prime}$ & $\mathrm{E} 100^{\circ} 16^{\prime} 33^{\prime \prime}$ & $3980 \mathrm{~m}$ & $\begin{array}{l}\text { Alpine mea- } \\
\text { dow }\end{array}$ & 2014 & 139.07 & Field measurement \\
\hline Maduo & $\mathrm{N} 34^{\circ} 54^{\prime} 40^{\prime \prime}$ & E98 $11^{\prime} 13^{\prime \prime}$ & $4207 \mathrm{~m}$ & Alpine steppe & 2015 & 113.23 & Field measurement \\
\hline
\end{tabular}

The original units of NPP in Fan (2003) and Luo et al. (2004) were $\mathrm{g} \mathrm{DM} \cdot \mathrm{m}^{-2} \cdot \mathrm{yr}^{-1}$ and $\mathrm{t} \mathrm{DM} \cdot \mathrm{ha}^{-1} \cdot \mathrm{yr}^{-1}$, respectively. We used 0.45 as the $\mathrm{C}$ content to convert dry matter (DM) to $\mathrm{C}$ to make these results comparable.

\section{Evaluation of methods and results}

\subsection{Estimation methods}

Each NPP estimation method has its own advantages and disadvantages. When applied to the TRHR, different estimation methods are confronted by different challenges and suitable for different conditions. As a result, NPP estimates acquired from these methods present different characteristics.

\subsubsection{Field measurements}

NPP obtained from field measurements is generally believed to be true NPP, and scholars 
often refer to the measured NPP as validation for other estimation methods. However, in practice, there are many uncertain factors inherent in field investigations, including (but not limited to) sample selection (whether human activities are present), sample content (whether litter is included), and calculation method (especially the belowground NPP). Differences in these factors can produce varied NPP results. Furthermore, NPP field measurements are mainly based on biomass surveys, so the measured NPP only contains newly produced biomass. Therefore, theoretically, NPP acquired from most field measurements is different from true NPP. The clarification and unification of NPP measuring methods and sampling criteria should become a top research priority (Gao et al., 2012).

\subsubsection{Climate model simulations}

In general, climate models are only driven by climate data without considering the effects of topography, soil property, availability of nutrients, human activities, and other influencing factors on vegetation productivity. In addition, climate models lack a sound theoretical basis and comprehensive ecophysiological mechanism. Consequently, climate models have low estimation accuracies and produce much larger NPP estimates. According to the estimated results in the TRHR (Table 1), NPP simulated from climate models was usually 2-4 times higher than NPP simulated from other models.

There are two main reasons for such a large difference. Firstly, Miami, Thornthwaite Memorial, and other climate-related models were based on empirical regressions between climatic conditions and measured NPP. Therefore, parameters used in these models may need to be adjusted for a specific region. However, previous studies all applied unadjusted parameters directly to estimate NPP in the TRHR and did not verify the estimated results as the potential NPP could not be verified using the measured NPP. Thus, NPP estimates based on climate models were substantially higher (Guo et al., 2013; Li and Zhang, 2014). The second reason for the significant difference is the fact that the TRHR is a traditional pastoral area. Human management and livestock activities are prominent in the TRHR, and the effects of grazing cannot be ignored; thus, NPP acquired from climate models is significantly different from the actual NPP. Although climate models are relatively simple and convenient to use, they tend to be rather limited in actual application due to low estimation accuracy.

\subsubsection{Remote sensing model simulations}

RS statistical models are able to accurately estimate NPP in a relatively small area; however, this type of model has poor universality. These models usually directly convert the scale from samples (ground observations) to pixels (remote sensing images) without considering the scale effect, and use a single regression model for all of the vegetation types. Besides, statistical models rely heavily on the measured NPP. These all greatly limit the application of RS statistical models to large-scale NPP studies (Gao et al., 2012).

RS parametric models are commonly used in the TRHR and can provide relatively high estimation accuracies (Shao and Fan, 2012). However, there are still many uncertainties in RS parametric models that need to be highlighted during NPP estimation (Zhang et al., 2011):

(1) As an important input of most RS parametric models, NDVI greatly affects the accuracy of NPP estimation. According to the previous studies (Yang and Piao, 2006; Zhang et al., 2013), NDVI cannot accurately reflect the actual state of vegetation growth when the 
coverage of vegetation is very low. In fact, snow, glaciers, bare soils, and rocks, as well as sparse vegetation, are widely distributed in the TRHR, especially in the western part, so the accuracy of remote-sensed NDVI data cannot be guaranteed. In addition, to overcome the interferences of clouds and cloud-shadows, the maximum-value composite (MVC) procedure is often used to produce composite NDVI images. Since the composite NDVI reflects the most optimal vegetation growth state during composite period, instead of the average growth state, this could lead to overestimation of NPP.

(2) Under low temperature conditions, model responses need to be evaluated in relation to the actual situations of the TRHR. For example, in the CASA model monthly NPP is equal to zero when the monthly mean temperature is below $-10^{\circ} \mathrm{C}$, and the soil water content remains unchanged and the same as in the previous month if the monthly mean temperature falls below $0^{\circ} \mathrm{C}$ (Zhou and Wang, 2003). However, grasslands in the TRHR are dominated by perennial, deciduous grasses. The aboveground part of grasses is shed annually to avoid the harsh winter, but the perennial underground part is still living. For the trees and shrubs in the TRHR, the aboveground part is partially alive in the winter. Thus, under low temperature conditions, GPP of the TRHR should be equal to zero and NPP should be negative. The treatment of setting NPP to zero in non-growing seasons causes NPP to be overestimated. In addition, it is soil temperature, not atmospheric temperature, that directly influences the soil moisture state. Even if the soil temperature drops below $0^{\circ} \mathrm{C}$ and the soil begins to freeze, the soil water content will decline significantly before it becomes stabilized (i.e., soil water is completely frozen), and therefore not remain the same as in the previous month.

(3) Models are not able to simulate the detailed changes in processes of NPP. As RS images only record instantaneous values, RS models are only able to estimate limited frequencies of NPP determined by the temporal resolution of RS input data. As a result, RS models can neither provide the detailed changes in processes of NPP, nor identify the key drivers of NPP changes or quantify the human impacts on NPP. In cases where the environment changes rapidly (such as heavy snowfall, outbreaks of pests and diseases, etc.), the reliability of RS models reduces substantially.

Despite the above-mentioned limitations, RS models are able to obtain relatively high estimation accuracies and calculation efficiencies at low costs. RS models are suitable for studies aimed at estimating vegetation standing biomass and its rate of change.

\subsubsection{Process model simulations}

As process models are yet to be specifically applied to the TRHR, this study only explores their suitability by analyzing the existing process models. The main challenges faced by process models are as follows:

(1) The phenology modules in the process models require comprehensive verification in the TRHR. Phenology, the timing of plant growth and development, is critical for biomass accumulation. An accurate simulation of phenology is a prerequisite for obtaining unbiased NPP estimates in the TRHR (Hidy et al., 2012). However, phenology models were generally established from data collected in specified areas, and did not work well when applied to larger spaces or other places. Currently, most process models, such as Biome-BGC, ORCHIDEE, and LPJ, simulate phenology based on empirical or semi-empirical relationships between phenological stages and climate factors. They assume that phenology is gen- 
erally controlled by temperature and moisture conditions in the environment, and the moisture is often described using precipitation (Jolly et al., 2005; Tian and Zeng, 2015). However, in the TRHR, although precipitation is not so much at the beginning of the growing season, soil water is sufficient for vegetation growth due to thawing of the widely distributed frozen soil. Simulation results based on the Biome-BGC also indicated that the start day of the growing season was significantly delayed (approximately in June) due to the high threshold of precipitation to start a new growing season in the model (related results are yet to be published).

(2) Most existing process models cannot accurately simulate the growth and litterfall processes of perennial, deciduous grasses. Most process models are able to simulate the basic biogeochemical processes for grasses, but their descriptions for herbaceous plants are too simple. In Biome-BGC, for example, grasses are comprised of only leaves and fine roots that all become litter at the end of the growing season. The regeneration and litterfall processes of perennial plants are usually controlled by user-defined or default turnover fractions in process models, and the senescence and litterfall processes are generally not considered separately, but dealt with as a single process. If process models are applied directly to estimate NPP in the TRHR without any modification, there is a strong possibility that carbon, nitrogen, and water cycles between different components of plants are simulated inadequately due to the coarse description of grasses. Since vegetation in the TRHR is dominated by perennial plants, the roots do not all die at the same rate and the underground perennial portion remains alive during the winter. Therefore, living and dead roots need to be distinguished, and turnover fractions of the underground fast-cycling portion and the perennial portion should be defined separately in process models, otherwise simulations of root development, soil respiration, litterfall, decomposition, and plant regeneration processes will all be affected, which will definitely impact NPP estimation.

(3) In general, hydrological simulations based on NPP process models are less than ideal. In the TRHR, frozen soils, including permafrost and seasonally frozen soil, are widespread and the thickness of the active layer varies greatly over time. Except for precipitation, underground ice melting and lateral flow are also important sources of soil water. However, most NPP process models have not yet adequately considered the impacts of frozen soils on hydrological processes. Precipitation is considered as the sole source of soil water, and the infiltration depth of precipitation is often set to a constant. These would lead to large simulation errors of soil water content, and further influence the calculation processes of soil evaporation, stomatal conductance, photosynthesis, and transpiration.

(4) Influences of human activities are usually modeled in a very simple manner and not spatially related. Most NPP process models, such as DLEM (Tian et al., 2010), CENTURY (Zhang et al., 2015b), and Biome-BGC (White et al., 2000) use simplified modules or just several parameters to reflect the impacts of human activities on biogeochemical processes. Currently, these models generally have no capacity to account for detailed spatial differences in their simulated results as human activities are not easily spatialized, so the practical applications of NPP process models to ecosystem management and planning are very limited.

(5) No process models have considered the impacts of wildlife on NPP. As a national nature reserve, there are various types and large numbers of wild animals living in the TRHR, including Pantholops hodgsonii, Procapra picticaudata, Equus kiang, and Procapra prze- 
przewalskii. In order to accurately simulate NPP in the TRHR, impacts of wild animals cannot be ignored.

Simulation accuracies of process models are not necessarily better than those of RS models (Gao et al., 2012). However, as process models can simulate plant physiological and ecological processes as well as the interactions and feedbacks within ecosystems, they are of more significance in the ecosystem management and early-warning analyses.

\subsubsection{RS-process coupled model simulations}

RS-process coupled models have strengthened the mechanisms behind some processes in RS models, and simultaneously have made the model parameterization and scale transformation in process models easier and more convenient. Although the GLOPEM-CEVSA model proposed by Wang et al. (2009) does not use a mechanistic model of photosynthesis, it simulates biomass allocation, respiration, litterfall, and decomposition processes within sound theoretical frameworks. GLOPEM-CEVSA has been well verified in the TRHR. Another RS-process coupled model, the MOD17A3 algorithm, calculates GPP based on a RS parametric model, and estimates autotrophic respiration from mechanisms. The estimated GPP and autotrophic respiration are then combined to obtain NPP (Running and Zhao, 2015). Although there have been a number of studies using the MODIS NPP product in the TRHR (Guo et al., 2006; Zhang et al., 2015a), there are few reports of the accuracy of the MODIS NPP product or MOD17A3 algorithm based on field verifications in the TRHR.

For the difficulties of large-scale phenology simulation, RS-process coupled models have provided effective solutions. For example, the RS-process coupled model, SiB2, utilizes continuous NDVI data to acquire phenological information (Sellers et al., 1996). BEPS model uses LAI data obtained every eight days to reflect phenological changes in vegetation (Sun et al., 2015). Similar to RS models, RS-process coupled models have deficiencies in providing forecasts and early warnings.

\subsection{Parameter values}

Many parameters used in NPP estimation methods have clear ecological significance. However, in real estimation processes, if the value of a certain parameter deviates wildly, a seemingly accurate result can still be produced by adjusting other parameters. In this case, NPP estimation becomes a purely mathematical game rather than a beneficial insight into mechanisms and changes in the ecosystem. Therefore, utilization of realistic and accurate parameters in the NPP estimation processes does have a significant impact on the development of NPP models and understanding of ecological environments. For brevity, this paper only covers some key parameters used in the processes of NPP estimation. Parameters discussed include the maximum LUE, ratio of underground biomass to aboveground biomass, ratio of live root biomass to total underground biomass, $\mathrm{C}$ content, and root turnover fraction.

\subsubsection{Maximum light use efficiency}

RS parametric models are the most commonly used models for NPP estimation in the TRHR. As an extremely important parameter in RS parametric models, values of the maximum LUE greatly affect NPP estimates. Potter et al. (1993) calculated the maximum LUE for global 
vegetation as $0.389 \mathrm{~g} \mathrm{C} \cdot \mathrm{MJ}^{-1}$; however, many studies have shown that this value was not suitable for the vegetation in China (Zhu et al., 2006). Running et al. (2000) used Biome-BGC to simulate values of the maximum LUE for different vegetation types worldwide. Wang (2013) and Wu et al. (2011) applied the result for grasslands $\left(0.608 \mathrm{~g} \mathrm{C} \cdot \mathrm{MJ}^{-1}\right)$ from Running et al. (2000) to estimate NPP of the TRHR. Zhu et al. (2006) simulated values of the maximum LUE for typical vegetation types in China at a national scale, and the values for grasslands/farmlands, forests, and shrubs were found to be $0.542 \mathrm{~g} \mathrm{C} \cdot \mathrm{MJ}^{-1}, 0.389-0.985$ $\mathrm{g} \mathrm{C} \cdot \mathrm{MJ}^{-1}$ (considering the differences between coniferous, broadleaf, and mixed forest types), and $0.429 \mathrm{~g} \mathrm{C} \cdot \mathrm{MJ}^{-1}$, respectively. Cai et al. (2013) directly used these results to simulate NPP of the TRHR. For the Qinghai Province, however, Wei and Wang (2010) calculated the maximum LUE to be only $0.649-0.908 \mathrm{~g} \mathrm{C} \cdot \mathrm{MJ}^{-1}, 0.114-0.538 \mathrm{~g} \mathrm{C} \cdot \mathrm{MJ}^{-1}$, and $0.115-0.326 \mathrm{~g} \mathrm{C} \cdot \mathrm{MJ}^{-1}$ for forests, shrubs, and grasslands, respectively.

Although the TRHR is subjected to intense solar radiation due to its high altitude, the energy fixed by photosynthesis is limited. Species of plant on the plateau have lower photosynthetic rates and quantum efficiency, as well as lower LUE, than those for the same species on the plain (Zhou, 2001). The direct application of the maximum LUE suitable for global or other areas to the TRHR might lead to an overestimation of NPP. This review suggests that, when estimating NPP in the TRHR, suitable values of the maximum LUE for grasslands, forests, and shrubs should be $0.115-0.326 \mathrm{~g} \mathrm{C} \cdot \mathrm{MJ}^{-1}, 0.389-0.908 \mathrm{~g} \mathrm{C} \cdot \mathrm{MJ}^{-1}$, and

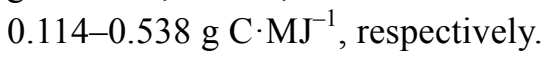

\subsubsection{Ratio of underground biomass to aboveground biomass}

To obtain NPP from field measurements, biomass needs to be measured first in most cases. Because aboveground biomass is relatively easy to measure, and direct access to underground biomass is difficult, many scholars have utilized the ratio of underground biomass to aboveground biomass (i.e., root to shoot, R/S) to estimate plant underground biomass. The $\mathrm{R} / \mathrm{S}$ ratio is commonly adopted in NPP estimation processes, particularly for grasslands. In this article, some results of R/S ratios for primary grassland types in the TRHR are summarized in Table 4 , which shows that $\mathrm{R} / \mathrm{S}$ ratios vary substantially among different studies. Although the R/S ratio carries a certain degree of uncertainty, most studies showed that for alpine meadow and alpine steppe, there was a good correlation between aboveground biomass and underground biomass, and $\mathrm{R} / \mathrm{S}$ ratios fell within a certain range of variation. Therefore, utilization of $\mathrm{R} / \mathrm{S}$ ratios to estimate grassland biomass and productivity in the TRHR remains a reliable approach (Ma et al., 2014). According to the field data obtained by

Table 4 Root to shoot $(\mathrm{R} / \mathrm{S})$ ratios of primary grassland types in the TRHR

\begin{tabular}{cccccc}
\hline $\begin{array}{c}\text { Alpine } \\
\text { meadow }\end{array}$ & $\begin{array}{c}\text { Alpine } \\
\text { steppe }\end{array}$ & $\begin{array}{c}\text { Temperate } \\
\text { steppe }\end{array}$ & Marsh & Reference & $\begin{array}{c}\text { Acquisition } \\
\text { mode }\end{array}$ \\
\hline 4.15 & $/$ & $/$ & $/$ & Fan, 2003 & Field measurement \\
6.8 & 5.2 & $/$ & $/$ & Yang et al., 2009 & Field measurement \\
7.92 & 4.42 & 4.32 & $/$ & Luo et al., 2002 & Field measurement \\
7.92 & 4.25 & 4.25 & 15.68 & Piao et al., 2004 & Literature review \\
9.19 & 9.49 & 9.19 & $/$ & Wang et al., 2008 & Literature review \\
6.5 & 6.2 & 6.4 & $/$ & Ma et al., 2014 & Literature review \\
\hline
\end{tabular}


Yang et al. (2009), variation ranges of R/S ratios for alpine meadow and alpine steppe were 0.8-13 and 1.4-12.7, respectively. For the entire alpine grasslands on the Qinghai-Tibet Plateau, the median $\mathrm{R} / \mathrm{S}$ ratio was approximately 5.8, which was greater than that of the global grasslands.

\subsubsection{Ratio of live root biomass to total underground biomass}

Only live roots are relevant to vegetation productivity. Thus, when estimating underground NPP in the field measurements, there is a need to distinguish between live and dead roots. The distinction is made subjectively, using color, density, and shape of the roots as distinguishing characteristics. Live roots are usually white or brown in color, whereas dead roots are often black. When roots are placed in water, denser roots sink to the bottom, usually indicating dead roots. In contrast, live roots tend to float. Furthermore, intact roots with a smooth appearance tend to be alive, whereas roots with shredded or folded skin tend to be dead.

Zhou (2001) conducted continuous observations of underground biomass in an alpine meadow ecosystem at Haibei station from May to September between 1980 and 1982, and found that the live root biomass was approximately $70 \%-80 \%$ of the total underground biomass. Fan et al. (2010b) assumed the ratio of live root biomass to total underground biomass to be 0.79 during their estimation of grassland NPP in the TRHR. However, according to our measured (unpublished) data obtained in the years of 2005, 2008, and 2015, this ratio was approximately $0.2-0.4$ for most sampling sites within the TRHR, and only at some sites in alpine swamp meadow did the ratio exceed 0.6. A good explanation for such a significant difference between these findings has yet to be determined. Possible explanations include different methods used to distinguish between live and dead roots and global climate change, which has significantly increased soil temperatures and decreased soil water content and consequently restricted root longevity compared to that measured in the $1980 \mathrm{~s}$.

\subsubsection{C content}

Calculations of NPP based on biomass require the C content when NPP needs to be expressed as C per unit time and space. Studies by Zhou (2001) and Zhao (2009) showed that $\mathrm{C}$ content of plants in the alpine Kobresia humilis Serg meadow ranged between $34 \%$ and $38 \%$. Research by Chang (2008) carried out in the Stipa purpurea alpine steppe revealed that the C content was between $21 \%$ and $39 \%$ (with an average of $29 \%$ ). Based on both previously published data and field measurements, Zheng et al. (2007) reported that the average $\mathrm{C}$ contents of trees, shrubs, and herbs were $46.22 \%, 45.93 \%$, and $37.13 \%$, respectively, and in herbaceous plants, average $\mathrm{C}$ contents of leaves, stems, and roots were $36.83 \%, 32.57 \%$, and $34.16 \%$, respectively. The $\mathrm{C}$ contents of herbaceous plants obtained from aforementioned studies were much lower than the commonly used range of $45 \%-50 \%$. However, most studies of grassland NPP estimation in the TRHR have assumed 0.45 as the C content (Fan, 2003; Zhang et al., 2015a), which has caused an overestimation of NPP. Therefore, for herbaceous plants in the TRHR, the C content should not exceed $40 \%$ in NPP estimation processes, whereas for forests and shrubs, the range of $45 \%-50 \%$ can be used.

\subsubsection{Root turnover fraction}

Root turnover fraction is defined as the proportion of root production or mortality during a 
certain period to the total root biomass (usually one year). A direct measurement of root turnover fraction has proven rather difficult. Gill et al. (2002) recommended three ways to estimate the root turnover fraction of grasslands. These include: (1) using the ratio of underground NPP to underground average, minimum, or maximum biomass to acquire root turnover fraction; (2) establishing the empirical relationship between root turnover fraction and aboveground NPP or climate data; and (3) assuming root turnover fraction as a constant value. Fan et al. (2010b) utilized the empirical relationship between root turnover fraction and aboveground NPP developed by Gill et al. (2002) to estimate root turnover fraction and NPP in the TRHR. In wetlands and marsh areas, they estimated root turnover fraction could exceed 0.7 using this method. In process models, however, constant root turnover fractions are usually used for different vegetation types. Gill et al. (2002) proposed that the root turnover fraction of global grasslands was approximately 0.65 . Wu et al. (2014) applied sequential coring, ingrowth cores, and a minirhizotron to investigate the root production and turnover fraction of grasses in an alpine meadow. The results indicated that different methods could produce very different root turnover fractions, and reliable values ranged between 0.29 and 0.63 . Therefore, in estimation processes of grassland NPP in the TRHR, we recommend root turnover fraction should be between 0.29 and 0.65 (Wu et al., 2011b). For wetlands and alpine swamp meadows, the root turnover fraction can be above 0.7 (Zhou, 2001; Fan et al., 2010a).

\subsection{Estimated results}

\subsubsection{Model accuracy}

There are several studies evaluating the estimation accuracy of different NPP models. Cai et al. (2013) performed correlation analysis between CASA-modeled NPP and measured NPP in the TRHR, and showed that the estimation accuracy of CASA was relatively ideal with the correlation coefficient reaching 0.8. In addition, Cai et al. (2013) compared NPP estimates of the CASA model with those of the Miami and Zhou Guangsheng models, and indicated that the latter produced higher estimates with lower accuracies. Fan et al. (2010b) calculated NPP and grassland yield based on GLO-PEM model, and verified the simulated yield with the measured yield at the same sites in the TRHR. The results indicated a good correlation between them $\left(\mathrm{R}^{2}=0.54, \mathrm{P}<0.01\right)$. In addition, Wang $(2013)$ used the correlation coefficient $(r)$, determination coefficient $\left(\mathrm{R}^{2}\right)$, and root mean square error (RMSE) as indicators to evaluate the estimation accuracies of different NPP models based on NPP measurements. Results showed that the performance of MOD17A3 algorithm was most accurate, followed by CASA model, while the Miami and CIM models were least accurate. Therefore, according to the existing evaluation results in the TRHR, RS-process coupled models generally have the best estimation accuracy, followed by RS models, and climate models display the lowest accuracy.

\subsubsection{Verification methods}

There are four main types of verification methods used in NPP estimation studies of the TRHR: (1) Biomass or grassland yield is obtained and converted to NPP, which is then compared with the simulated results (Cai et al., 2013; Wang, 2013); (2) simulated grassland NPP is first converted to grassland yield and then compared to the investigated yield data 
(Wang et al., 2009; Fan et al., 2010b); (3) simulated NPP is compared with the results from previous studies in the same (or a similar) region (Zhang et al., 2014; Chen, 2015); and (4) direct comparisons are conducted using MODIS NPP products (Wo et al., 2014). In terms of NPP verification, two issues require additional attention. First, field data of underground NPP, which is the primary component of total NPP in the TRHR, is extremely underrepresented compared to aboveground NPP. Currently, underground NPP is primarily obtained from conversions of the aboveground biomass or aboveground NPP. However, different studies use various parameter values in conversion processes including $\mathrm{R} / \mathrm{S}$ ratio, root turnover fraction, and $\mathrm{C}$ content, all of which can affect the estimates of NPP. The second is that only the final simulated NPP is actually verified. Intermediate variables are not verified nor do they receive adequate attention. Since only the NPP is verified, estimation processes become "black boxes" in which model applications are little more than "games of parameter adjustment". If only NPP is correct and intermediate outputs are largely erroneous, this will introduce great uncertainty into ecosystem simulations and early-warning analyses.

\subsubsection{Evaluation of results}

According to Chapin III et al. (2002), NPP includes the new biomass produced by plants, the soluble organic compounds that are diffused or secreted by roots, the carbon transferred into microbes that are symbiotically associated with roots (nitrogen-fixing bacteria and mycorrhizae), losses to herbivory and mortality, and the volatile emissions that are lost from leaves to the atmosphere. Most field measurements of NPP document only the newly produced plant biomass and therefore probably underestimate the true NPP. According to Chapin III et al. (2002), only the NPP involved in root secretions accounts for more than $20 \%$ of the true NPP.

The TRHR has always been a traditional pastureland. Based on years of foraging surveys and sampling, the annual intake of livestock accounts for approximately $41.48 \%$ of grassland aboveground NPP (Zhou, 2001). NPP consumed by wild animals is also significant. In 2013, according to preliminary statistics, there were more than 200,000 wild animals inhabiting Maduo County alone, including Pantholops hodgsonii, Procapra picticaudata, Equus kiang, and Procapra przewalskii, which greatly exceed the current livestock numbers (about 130,000). The consumption of a Pantholops hodgsonii is equivalent to that of six domestic sheep (Song, 2013). In addition, rodents have become a serious problem in some areas of the TRHR (Shao and Fan, 2012). According to conservative estimates, a medium level of rodent density would result in 20\%-30\% consumption of available livestock pastures (Zhou, 2001). Therefore, a considerable proportion of biomass has already been consumed by herbivores before it can be measured, so even the new biomass measured in field studies is an underestimate of biomass production.

Assuming that the ratio of aboveground NPP to underground NPP for alpine grasslands in the TRHR is approximately 1:2 (Zhou, 2001; Luo et al., 2004), aboveground NPP accounts for approximately $30 \%$ of the total NPP. Livestock grazing consumes approximately $12 \%$ of the total NPP. Consumption by wild animals is no less than that of the livestock, so it is also estimated at $12 \%$ of the total NPP. Intake by rodents is calculated as $20 \%$ of livestock consumption, and thus, accounts for approximately $2 \%$ of the total NPP. Root secretions are assumed to comprise approximately $20 \%$ of the total NPP. Therefore, in summary, most of 
the NPP obtained from field measurements in the TRHR might have underestimated the true NPP by at least $40 \%$. If models do not include or cannot reflect these factors causing NPP underestimation, but rather directly take the underestimated NPP as the true NPP in the simulation processes (mainly via parameter calibration and result verification), the estimated NPP based on these models will also be underestimated. Therefore, during NPP estimation processes, the content of simulated NPP and measured NPP must be consistent.

\section{Conclusions}

The main conclusions of this study can be summarized as follows:

(1) NPP estimation methods can be broadly divided into two categories: field measurements and model simulations. NPP models include climate models, RS models, process models, and RS-process coupled models. The NPP obtained from field measurements is generally considered as the true NPP, and it is often applied to validate the results of other NPP estimation methods. Among different NPP models, RS-process coupled models are generally most accurate, followed by RS models, while climate models are least accurate.

(2) The potential NPP of all the vegetation in the TRHR was approximately $453.23 \pm$ $252.30 \mathrm{~g} \mathrm{C} \cdot \mathrm{m}^{-2} \cdot \mathrm{yr}^{-1}$, and the actual NPP was $161.87 \pm 63.40 \mathrm{~g} \mathrm{C} \cdot \mathrm{m}^{-2} \cdot \mathrm{yr}^{-1}$. The potential NPP of grassland was approximately $283.28 \pm 170.44 \mathrm{~g} \mathrm{C} \cdot \mathrm{m}^{-2} \cdot \mathrm{yr}^{-1}$, and the actual NPP was $130.79 \pm 73.27 \mathrm{~g} \mathrm{C} \cdot \mathrm{m}^{-2} \cdot \mathrm{yr}^{-1}$. Across different vegetation types, estimated mean NPP displayed the following trend: forest $>$ farmland $>$ grassland $>$ desert.

(3) NPP simulated from climate models was usually 2-4 times higher than NPP simulated from other estimation models. Although RS parametric models are commonly used in the TRHR and provide relatively high estimation accuracies, there are still many uncertainties that should be highlighted during NPP estimation. Because of the particular alpine environments, most of the current process models cannot be directly applied to estimate NPP in the TRHR. Additionally, although RS-process coupled models can compensate for some weaknesses of RS and process models, they still have deficiencies in providing forecasts and early warnings.

(4) Most NPP studies have overestimated the maximum LUE for grasslands in the TRHR. The applied ratio of underground biomass to aboveground biomass ( $\mathrm{R} / \mathrm{S}$ ratio) varied substantially among different studies. The assumed ratio of live root biomass to total underground biomass was relatively high, and the measured ratio ranged from $20 \%$ to $40 \%$. The $\mathrm{C}$ content of herbaceous plants in the TRHR was much lower than the commonly used range of $45 \%-50 \%$. Recommended root turnover fraction in the TRHR was between 0.29 and 0.65 , whereas for wetlands and alpine swamp meadows, root turnover fraction can be above 0.7.

(5) At present, validation for NPP estimates is not comprehensive, and it needs more effort and in-depth research involving the verification method and content. According to preliminary estimates, currently most of the NPP obtained from field measurements in the TRHR might have underestimated the true NPP by at least $40 \%$. If models directly consider the underestimated NPP as the true NPP in the modeling and calculation processes, the estimated NPP will also be underestimated. Therefore, simulated NPP and measured NPP must be consistent in meaning during NPP estimation processes. 


\section{Outlook}

(1) An overall strengthening of data infrastructure in the TRHR is required. Because of the harsh natural environments, fixed and semi-fixed sampling plots, ecological research stations, and micrometeorological tower sites are far from adequate and are distributed unevenly in the TRHR. Furthermore, long-term and systematic observations are severely lacking, and important ecological data including climate, vegetation, soil, and hydrology generally have coarse resolution and bad currency. These all contribute to the challenges of dynamic and unbiased NPP estimation. In recent years, a great deal of money and technology has been invested in the TRHR to construct a network of ecological monitoring stations based on the requirements of ecological protection and construction. These stations on the ground, combined with satellites, have formed a preliminary air-ground environmental monitoring system. It is hoped that, based on this preliminary system, ecological and environmental monitoring in the TRHR can be performed under stable procedures in the future to complete the tasks of data collection and sharing.

(2) An emphasis on the development of process models applicable to the TRHR is required. Process models can be used not only to estimate NPP but also to describe and forecast changes in NPP. However, most existing process models are not capable of accurately simulating the unique ecological processes in alpine environments of the TRHR. Therefore, there is an urgent need to develop NPP process models that can accurately simulate the phenological changes, regeneration, and litterfall processes of perennial, deciduous grasses, presence of the permafrost, and impacts of frozen soil on the water cycle in the TRHR. Furthermore, as the TRHR covers such a wide area, substantial ecological variation has been observed. The spatial differences within the TRHR should be taken into consideration during model development and simulation processes.

(3) The development of NPP models that can depict human activities and wildlife impacts is required. Of all the various NPP models, climate models describe no effects of disturbance factors other than climate change. While RS models can reflect human activities and wildlife impacts in the results, they cannot simulate the impact processes nor can they quantify the degree of influences. Although process models and RS-process coupled models are able to simulate the influences of both human and wildlife activities on NPP estimation, the relevant modules within them are relatively simple, and there has been almost no consideration of wild animals. As a national nature reserve, wildlife numbers in the TRHR have rapidly increased over the years, and it is likely that human activities will also increase with the establishment of national parks in the area. Therefore, it is crucial for the TRHR to develop NPP models that include both human activities and wildlife impacts.

(4) The development of an easy operating platform to run regional-scale models is required. There are a number of models for NPP estimation; however, the actual application of these models to the TRHR at the regional scale might be challenging for scientific researchers or technical staff due to the complexities of the models and laborious tasks of data preparation. These difficulties have greatly limited both the breadth and depth of NPP applications. Therefore, developing an easy operating platform to run regional-scale NPP models deserves high priority.

(5) A convergence of NPP estimates with environmental management practices is also 
required. NPP not only reflects the growth state of vegetation but also serves as an important indicator of ecosystem health. Changes in NPP directly affect ecosystem processes and functions that have a profound impact on ecosystem services, which ultimately influences the wellbeing of human populations. Therefore, linking NPP estimation to ecosystem carbon trading, ecological assets valuation, conservation strategy simulation, and other environmental management practices is important for the promotion of NPP studies in the TRHR.

\section{References}

Cai Y L, Zheng Y F, Wang Y L et al., 2013. Analysis of terrestrial net primary productivity by improved CASA model in Three-River Headwaters Region. Journal of Nanjing University of Information Science and Technology (Natural Science Edition), 5(1): 34-42. (in Chinese)

Chang T J, 2008. The distribution pattern of carbon reserve in Northern Tibet alpine grassland ecosystem [D]. Linzhi: Agriculture and Animal Husbandry College of Tibet University. (in Chinese)

Chapin III F S, Matson P A, Mooney H A, 2002. Principles of Terrestrial Ecosystem Ecology. New York: Springer, 127-128.

Chen J F, Liu C, Xu J B, 2011. Research on the remote sensing monitoring of grass productivity based on TM-NDVI. Journal of Anhui Agricultural Sciences, 39(12): 7365-7366. (in Chinese)

Chen L J, 2015. The study on the temporal and spatial variation of NPP and its driving factors in Sanjiangyuan Nature Reserve [D]. Taigu: Shanxi Agricultural University. (in Chinese)

Cramer W, Field C B, 1999. Comparing global models of terrestrial net primary productivity (NPP): Introduction. Global Change Biology, 5(S1): iii-iv.

Cramer W, Kicklighter D W, Bondeau A et al., 1999. Comparing global models of terrestrial net primary productivity (NPP): Overview and key results. Global Change Biology, 5(S1): 1-15.

Du Y E, Liu B K, Guo Z G, 2011. Changes of forage biomass of grasslands during the growing season in the Qinghai-Tibetan Plateau based on MODIS data. Pratacultural Science, 28(6): 1117-1123. (in Chinese)

Fan J W, Shao Q Q, Liu J Y et al., 2010a. Dynamic changes of grassland yield in Three River Headwater Region from 1988 to 2005. Acta Agrestia Sinica, 18(1): 5-10. (in Chinese)

Fan J W, Shao Q Q, Liu J Y et al., 2010b. Assessment of effects of climate change and grazing activity on grassland yield in the Three Rivers Headwaters Region of Qinghai-Tibet Plateau, China. Environmental Monitoring and Assessment, 170(1): 571-584.

Fan Y J, 2003. Effects of fencing and grazing on plant morphology, community characteristics and carbon balance of Kobresia pygmaea meadow in the Three Headwater Regions [D]. Lanzhou: Gansu Agricultural University. (in Chinese)

Fang J Y, Tang Y H, Lin J D et al., 2000. Global Ecology: Climate Change and Ecological Responses. Beijing: Higher Education Press; Heidelberg: Springer Press, 191. (in Chinese)

Feng X F, Liu G H, Chen S P et al., 2004. Study on process model of net primary productivity of terrestrial ecosystems. Journal of Natural Resources, 19(3): 369-378. (in Chinese)

Feng X F, Sun Q L, Lin B, 2014. NPP process models applied in regional and global scales and responses of NPP to the global change. Ecology and Environmental Sciences, 23(3): 496-503. (in Chinese)

Gao T, Xu B, Yang X C et al., 2012. Review of researches on biomass carbon stock in grassland ecosystem of Qinghai-Tibetan Plateau. Progress in Geography, 31(12): 1724-1731. (in Chinese)

Gill R A, Kelly R H, Parton W J et al., 2002. Using simple environmental variables to estimate belowground productivity in grasslands. Global Ecology \& Biogeography, 11(1): 79-86.

Guo L Y, Wu R, Wang Q C et al., 2008. Influence of climate change on grassland productivity in Xinghai County in the source regions of Yangtze River. Chinese Journal of Grassland, 30(2): 5-10. (in Chinese)

Guo P P, Yang D, Wang H et al., 2013. Climate change and its effects on climatic productivity in the Three-River Headwaters Region in 1960-2011. Chinese Journal of Ecology, 32(10): 2806-2814. (in Chinese) 
Guo X Y, He Y, Shen Y P et al., 2006. Analysis of the terrestrial NPP based on the MODIS in the source regions of Yangtze and Yellow rivers from 2000 to 2004. Journal of Glaciology and Geocryology, 28(4): 512-518. (in Chinese)

Han B, 2015. Modeling aboveground biomass of alpine grassland in the Three-River Headwaters Region based on remote sensing data [D]. Huainan: Anhui University of Science \& Technology. (in Chinese)

Hidy D, Barcza Z, Haszpra L et al., 2012. Development of the Biome-BGC model for simulation of managed herbaceous ecosystems. Ecological Modelling, 226: 99-119.

Jolly W M, Nemani R R, Running S W et al., 2005. A generalized, bioclimatic index to predict foliar phenology in response to climate. Global Change Biology, 11: 619-632.

Kumar M, Monteith J L, 1981. Remote sensing of crop growth. In: Plants and the Daylight Spectrum. London: Academic Press, 133-144.

Li H M, 2010. Assessment of climate productivity of natural grassland in the Three Rivers Source Regions in Qinghai. Journal of Anhui Agricultural Sciences, 38(12): 6414-6416, 6460. (in Chinese)

Li H M, Zhang A L, 2014. Response of grassland climate productivity to climate change in Sanjiangyuan Regions. Journal of Huazhong Agricultural University (Social Sciences Edition), 1: 124-130. (in Chinese)

Li L, Zhu X D, Zhou L S et al., 2004. Climatic changes over headwater of the Three-River-Area and its effect on ecological environment. Meteorological Monthly, 30(8): 18-21. (in Chinese)

Lieth H, 1973. Primary production: Terrestrial ecosystem. Human Ecology, 1(4): 303-332.

Lieth H, Whittaker R H, 1975. Primary Production of the Biosphere. New York: Springer-Verlag Press, 1-10.

Lin H L, 2009. A new model of grassland net primary productivity (NPP) based on the integrated orderly classification system of grassland. In: Proceedings of the Sixth International Conference on Fuzzy Systems and Knowledge Discovery: 52-56.

Liu J, Chen J M, Cihlar J et al., 1997. A process-based boreal ecosystem productivity simulator using remote sensing inputs. Remote Sensing of Environment, 62(2): 158-175.

Liu X F, Ren Z Y, Lin Z H et al., 2013. The spatial-temporal changes of vegetation coverage in the Three-River Headwater Region in recent 12 years. Acta Geographica Sinica, 68(7): 897-908. (in Chinese)

Luo T X, Li W H, Zhu H Z, 2002. Estimated biomass and productivity of natural vegetation on the Tibetan Plateau. Ecological Applications, 12(4): 980-997.

Luo T X, Pan Y, Ouyang H et al., 2004. Leaf area index and net primary productivity along subtropical to alpine gradients in the Tibetan Plateau. Global Ecology and Biogeography, 13(4): 345-358.

Ma A N, Yu G R, He N P et al., 2014. Above- and below-ground biomass relationships in China's grassland vegetation. Quaternary Sciences, 34(4): 769-776. (in Chinese)

$\mathrm{Ma}$ X L, 2008. The monitoring of rangeland resources productivity of Qinghai Province based on 3S technologies [D]. Lanzhou: Lanzhou University. (in Chinese)

Monteith J L, 1972. Solar radiation and productivity in tropical ecosystems. Journal of Applied Ecology, 9: $747-766$.

Piao S L, Fang J Y, He J S et al., 2004. Spatial distribution of grassland biomass in China. Acta Phytoecologica Sinica, 28(4): 491-498. (in Chinese)

Piao S, Tan K, Nan $\mathrm{H}$ et al., 2012. Impacts of climate and $\mathrm{CO}_{2}$ changes on the vegetation growth and carbon balance of Qinghai-Tibetan grasslands over the past five decades. Global and Planetary Change, 98/99: 73-80.

Potter C S, Randerson J T, Field C B et al., 1993. Terrestrial ecosystem production: A process model based on global satellite and surface data. Global Biogeochemical Cycles, 7: 811-841.

Qi W W, Niu H S, Wang S P et al., 2012. Simulation of effects of warming on carbon budget in alpine meadow ecosystem on the Tibetan Plateau. Acta Ecologica Sinica, 32(6): 1713-1722. (in Chinese)

Qin D H, 2014. Ecological protection and sustainable development in the Three-River Headwater Region. Beijing: Science Press, 1-5. (in Chinese)

Ruimy A, Saugier B, Dedieu G, 1994. Methodology for the estimation of terrestrial net primary production from remotely sensed data. Journal of Geophysical Research: Atmospheres (1984-2012), 99(D3): 5263-5283.

Running S W, 2012. A measurable planetary boundary for the biosphere. Science, 337(6101): 1458-1459. 
Running S W, Thornton P E, Nemani R et al., 2000. Global terrestrial gross and net primary productivity from the earth observing system. In: Sala O, Jackson R, Mooney H. Methods in Ecosystem Science. New York: Springer Verlag, 44-57.

Running S W, Zhao M S, 2015. Daily GPP and annual NPP (MOD17A2/A3) Products User's Guide (version 3.0). Missoula, USA: The University of Montana.

Sellers P J, Tucker C J, Collatz G J, 1996. A revised land surface parameterization (SiB2) for atmospheric GCMs Part II: The generation of global fields of terrestrial biophysical parameters from satellite data. Journal of Climate, 9(4): 706-737.

Shao Q Q, Fan J W, 2012. Integrated Monitoring and Evaluation of Ecosystems in the Three-River Headwater Region. Beijing: Science Press, 15-29, 167-172, 479. (in Chinese)

Shao Q Q, Zhao Z P, Liu J Y et al., 2010. The characteristics of land cover and macroscopical ecology changes in the source region of three rivers on Qinghai-Tibet Plateau during last 30 years. Geographical Research, 29(8): 1439-1451. (in Chinese)

Song F L, 2013. Challenges for the Three-River Headwater Region. The Economic Observer, 2013-1-14. (in Chinese)

Sun Q L, Feng X F, Liu M X et al., 2015. Estimation and analysis of net primary productivity in Wuling mountainous area based on remote sensing. Journal of Natural Resources, 30(10): 1628-1640. (in Chinese)

Tang H Y, Xiao F J, Zhang Q et al., 2006. Vegetation change and its response to climate change in Three-River Source Region. Advances in Climate Change Research, 2(4): 177-180. (in Chinese)

Tian D X, Zeng X D, 2015. Research progress in dynamic vegetation model phenology schemes. Climatic and Environmental Research, 20(6): 726-734.

Tian H Q, Liu M L, Zhang C et al., 2010. The dynamic land ecosystem model (DLEM) for simulating terrestrial processes and interactions in the context of multifactor global change. Acta Geographica Sinica, 65(9): 1027-1047. (in Chinese)

Wang C, 2013. Study on simulation methods of alpine grassland net primary productivity in Three Rivers Source Region of Tibetan Plateau, China [D]. Lanzhou: Lanzhou University. (in Chinese)

Wang J B, Liu J Y, Shao Q Q et al., 2009. Spatial-temporal patterns of net primary productivity for 1988-2004 based on GLOPEM-CEVSA model in the "Three-River Headwaters" region of Qinghai Province, China. Chinese Journal of Plant Ecology, 33(2): 254-269. (in Chinese)

Wang W, Peng S S, Fang J Y, 2008. Biomass distribution of natural grasslands and its response to climate change in North China. Arid Zone Research, 25(1): 91-97. (in Chinese)

Wei Y X, Wang L W, 2010. The study on simulating light use efficiency of vegetation in Qinghai Province. Acta Ecologica Sinica, 30(19): 5209-5216. (in Chinese)

White M A, Thornton P E, Running S W et al., 2000. Parameterization and sensitivity analysis of the Biome-BGC terrestrial ecosystem model: Net primary production controls. Earth Interactions, 4(3): 1-85.

Wo X, Wu L C, Zhang J P et al., 2014. Estimation of net primary production in the Three-River Headwater Region using CASA model. Journal of Arid Land Resources and Environment, 28(9): 45-50. (in Chinese)

Wu H, An R, Li X X et al., 2011a. Remote sensing monitoring of grassland degradation based on NPP change in the Maduo County of the sources region of Yellow River. Pratacultural Science, 28(4): 536-542. (in Chinese)

Wu Y, Wu J, Deng Y et al., 2011b. Comprehensive assessments of root biomass and production in a Kobresia humilis meadow on the Qinghai-Tibetan Plateau. Plant Soil, 338: 497-510.

Wu Y B, Che R X, Ma S et al., 2014. Estimation of root production and turnover in an alpine meadow: Comparison of three measurement methods. Acta Ecologica Sinica, 34(13): 3529-3537. (in Chinese)

Xiao T, Liu J Y, Shao Q Q, 2009. A simulation on changes in vegetation productivity in "Three River Sources" nature reserve, Qinghai province over past 20 years. Journal of Geo-information Science, 11(5): 557-565. (in Chinese)

$\mathrm{Xu} \mathrm{H} \mathrm{H,} \mathrm{2010.} \mathrm{Effects} \mathrm{of} \mathrm{different} \mathrm{grazing} \mathrm{systems} \mathrm{on} \mathrm{carbon} \mathrm{balance} \mathrm{in} \mathrm{Stipa} \mathrm{breviflora} \mathrm{desert} \mathrm{steppe} \mathrm{[D].} \mathrm{Bei-}$ jing: Chinese Academy of Agricultural Sciences. (in Chinese)

Yan L, Zhou G S, Wang Y H et al., 2015. The spatial and temporal dynamics of carbon budget in the alpine 
grasslands on the Qinghai-Tibetan Plateau using the Terrestrial Ecosystem Model. Journal of Cleaner Production, 107(16): 195-201.

Yang Y H, Fang J Y, Ji C J et al., 2009. Above- and belowground biomass allocation in Tibetan grasslands. Journal of Vegetation Science, 20(1): 177-184.

Yang Y H, Piao S L, 2006. Variations in grassland vegetation cover in relation to climatic factors on the Tibetan Plateau. Journal of Plant Ecology, 30(1): 1-8. (in Chinese)

Ye J S, 2010. Response of vegetation net primary productivity to climate change on the Tibetan Plateau. Lanzhou: Lanzhou University. (in Chinese)

Zhang G L, Zhang Y J, Dong J W et al., 2013. Green-up dates in the Tibetan Plateau have continuously advanced from 1982 to 2011. PNAS, 110(11): 4309-4314.

Zhang J P, Liu C L, Hao H G et al., 2015a. Spatial-temporal change of carbon storage and carbon sink of grassland ecosystem in the Three-River Headwaters Region based on MODIS GPP/NPP data. Ecology and Environmental Sciences, 24(1): 8-13. (in Chinese)

Zhang M L, Jiang W L, Chen Q G et al., 2011. Research progress in the estimation models of grassland net primary productivity. Acta Agrestia Sinica, 19(2): 356-366. (in Chinese)

Zhang Q Y, Li P, Zong Y Z et al., 2015b. Research and application of CENTURY model in different ecological systems. Journal of Shanxi Agricultural Sciences, 43(11): 1563-1566. (in Chinese)

Zhang X, 1992. Estimation and distribution of net primary productivity of natural vegetation in China. Natural Resources, 1: 15-21. (in Chinese)

Zhang Y, Chen H Y, Li J L, 2014. Quantitative estimation for net primary productivity of Three-Rivers Source Ecosystem in Recently 10 years. Tianjin Agricultural Sciences, 20(10): 25-28. (in Chinese)

Zhang Y Q, Tang Y H, Jiang J et al., 2007. Characterizing the dynamics of soil organic carbon in grasslands on the Qinghai-Tibetan Plateau. Science in China Series D (Earth Sciences), 50(1): 113-120.

Zhao X Q, 2009. Alpine Meadow Ecosystem and Global Change. Beijing: Science Press, 169, 219-221. (in Chinese)

Zheng L Y, 2006. Study on dynamic change of NPP and grassland change in Northern Tibet based on remote sensing and biological processes model BEPS [D]. Beijing: Chinese Academy of Meteorological Sciences. (in Chinese)

Zheng W J, Bao W K, Gu B et al., 2007. Carbon concentration and its characteristics in terrestrial higher plants. Chinese Journal of Ecology, 26(3): 307-313.

Zhou C P, Ouyang H, Wang Q X et al., 2004. Estimation of net primary productivity in Tibetan Plateau. Acta Geographica Sinica, 59(1): 74-79. (in Chinese)

Zhou G S, Wang Y H, 2003. Global Ecology. Beijing: China Meteorological Press, 82-102. (in Chinese)

Zhou G S, Zhang X S, 1995. A natural vegetation NPP model. Acta Phytoecologica Sinica, 19(3): 193-200. (in Chinese)

Zhou X M, 2001. Chinese Kobresia Meadow. Beijing: Science Press, 132-133, 146-195. (in Chinese)

Zhu W Q, Pan Y Z, He H et al., 2006. Simulation of maximum light use efficiency of typical vegetation in China. Chinese Science Bulletin, 51(6): 700-706. (in Chinese)

Zhuang Q, He J, Lu Y et al., 2010. Carbon dynamics of terrestrial ecosystems on the Tibetan Plateau during the 20th century: An analysis with a process-based biogeochemical model. Global Ecology and Biogeography, 19(5): 649-662. 